\title{
Moisture Sorption Isotherms And Thermodynamic Properties Of Urtica Dioica Leaves
}

\author{
Abdelkader Lamharrar, PhD \\ Ali Idlimam, PhD \\ Mohammed Kouhila, PhD
}

Laboratory of Solar Energy and Medicinal Plants,

Teacher's Training College, Cadi Ayyad University, Marrakesh, Morocco

Lamya Lahnine, PhD Condidate

ERIDDECV (Research Team of Innovation and Sustainable Development \&

Expertise in Green Chemistry), Department of Chemistry,

Cadi Ayyad University, Marrakesh 40000, Morocco

Hind Mouhanni, PhD

Higher Institute of Marine Fisheries, Agadir, Morocco

doi: 10.19044/esj.2016.v12n24p376 URL:http://dx.doi.org/10.19044/esj.2016.v12n24p376

\begin{abstract}
Urtica dioica is a Moroccon endemic plant of used for its virtues in traditional medicine. Thus, it is necessary to study the effect of preservation processes on the storage conditions of the plant. The static gravimetric method was used to determine sorption isotherms of Urtica dioica leaves at three temperatures (40,50 and $\left.60^{\circ} \mathrm{C}\right)$ and in the range of water activity $\left(a_{w}\right)$ ranging from 0.0572 to 0.898 . Six mathematical models were used to fit the experimental data. The Enderby and Peleg models were found to be the most suitable for describing the sorption curves. The optimal water activity for conservation of Urtica dioica leaves was determined. Isosteric heats of desorption and adsorption were calculated by applying the ClausiusClapeyron equation to the sorption isotherms at different temperatures; it decreased with increasing moisture content. A linear relation exists between the enthalpy and entropy of the sorption reaction.
\end{abstract}

Keywords: Enthalpy, Entropy, Hysteresis, Mathematical models, Sorption isotherms

\section{Introduction}

The medicinal and aromatic plants have a great importance for both the pharmaceutical industry and the traditional medecine. The stability of a 
dehydrated medicinal plant is influenced by its water activity. Urtica dioica is known as nettle in Morocco Its root and leaf, which contains active pharmacological compounds influencing cytological and physiological processes in the body, are used for medical purposes (Krystofova et al., 2010). This plant had been used as a diuretic and as a means of treating Arthritis and rheumatic diseases in the past (Bellakhdar, 1997).

The determination of sorption isotherms is a necessary step in the study of the drying and the preservation action of PAM, because it determining the equilibrium moisture content and offers valuable information on the balance hygroscopic product (Lamharrar et al ., 2007). In this study, temperatures of $30^{\circ} \mathrm{C}, 40^{\circ} \mathrm{C}$, and $50^{\circ} \mathrm{C}$ were chosen, to typify tropical storage conditions. Using an experimental approach, the equilibrium curves are determined by the saturated salt solution method. The experimental sorption curves are described by six different models to identify the most appropriate mathematical model for a better description of the product equilibrium state. Then, the experimental data the water activity optimal for the storage of Urtica dioica leaves were investigated.

Further analysis of sorption isotherm data by application of thermodynamic principals can provide information regarding differential enthalpy or the isosteric heat of sorption and differential entropy. Differential enthalpy of sorption gives an indication of the amount of bound water existing in the product. The differential entropy of material is proportional to the number of its available sorption sites at a specific energy level (Arsalan and Togrul, 2006). Subsequently we determine the thermodynamic functions (differential enthalpy, differential entropy). Moreover, we recognized the linear relation exists between the enthalpy and entropy of the sorption reaction.

\section{Materials and methods \\ Experimental procedure}

The plant Urtica dioica used in our study was collected at Tahanouat, Marrakesh Morocco. The hygroscopic equilibrium could be achieved by a dynamic or static method. In the present work, a static method is used. The method is based on the use of saturated salt solutions to maintain a fixed relative humidity $\mathrm{Rh}$. The mass transfers between the product and the ambient air are assured by natural diffusion of the water vapor. The atmosphere surrounding the product has a fixed relative humidity for every working temperature imposed on the system.

Six salts were chosen $\left\{\mathrm{KOH},\left(\mathrm{MgCl}_{2}, 6 \mathrm{H}_{2} \mathrm{O}\right), \mathrm{K}_{2} \mathrm{CO}_{3}, \mathrm{NaNO}_{3}, \mathrm{KCl}\right.$ and $\left.\left(\mathrm{BaCl}_{2}, 2 \mathrm{H}_{2} \mathrm{O}\right)\right\}$ so as to have a range of water activity $\left(a_{w}\right)$ of $0.0572-$ 0.0898 (Greenspan, 1977). The experimental apparatus consisted of six glass jars of 1 liter each with an insulted lid. Every glass jar was filled to quarter 
depth with a saturated salt solution. Duplicated samples each of $0.2 \mathrm{~g}$ $( \pm 0.0001 \mathrm{~g})$ for desorption and $0.1 \mathrm{~g}( \pm 0.0001 \mathrm{~g})$ for adsorption were weighed and placed into the glass jars. The weight recording period was about 3 days. This procedure continued until the weight was constant. The equilibrium moisture content of each sample was determined in a drying oven at $105{ }^{\circ} \mathrm{C}$ for $24 \mathrm{~h}$. The hygroscopic equilibrium Utica dioica leaves was reached in then days for desorption and eighth days for adsorption.

Thus, the difference of mass before $\left(M_{w}\right)$ and after $\left(M_{d}\right)$ drying determines their equilibrium moisture content $\left(\mathrm{EMC}=X_{e q}\right)$ of the product at hygroscopic equilibrium:

$$
X_{e q}=\frac{M_{w}-M_{d}}{M_{d}}
$$

\section{Modelling equations}

The relationship between EMC, water activity, and temperature for Urtica dioica was predicted in literature by several mathematical models (Al-Muhtaseb et al., 2004). In our study six models have been applied: modified Henderson's model, modified Oswin's model, modified Halsey, model Enderby's model, GAB's model and Peleg's model. The equations expressing those models are given below in Table 1.

$\mathrm{X}_{\mathrm{eq}}$ represents equilibrium moisture content (\%MS); $a_{w}$ water activity; A, B, C and D coefficients, dependant to the temperature or not, to determine by smoothing the experimental curves of sorption and $\theta$ the temperature in ${ }^{\circ} \mathrm{C}$.

Table 1: Mathematical models used in our study

\begin{tabular}{|c|c|c|}
\hline Model's name & Expression of the model & References \\
\hline GAB & $X_{e q}=\frac{A B C a_{w}}{\left[1-B a_{w}\right]\left[1-B a_{w}+B C a_{w}\right.}$ & $\begin{array}{c}\text { (Vanden Berg and Bruin, } \\
\text { 1981) }\end{array}$ \\
\hline Modified Henderson & $X_{e q}=\left[\frac{-\ln \left(1-a_{w}\right)}{A(\theta+B)}\right]^{1 / C}$ & (Thompson et al., 1986) \\
\hline Peleg & $X_{e q}=A\left(a_{w}\right)^{C}+B\left(a_{w}\right)^{D}$ & (Peleg, 1993) \\
\hline Modified Halsey & $X_{e q}=\left[\frac{(-\exp (A+B \cdot \theta)}{\ln \left(a_{w}\right)}\right]^{1 / C}$ & (Iglesias and Chirife, 1976) \\
\hline Modified Oswin & $X_{e q}=(A+B . \theta)\left[\frac{a_{w}}{1-a_{w}}\right]^{C}$ & (Oswin, 1946) \\
\hline Enderby & $X_{e q}=\left[\frac{A}{1-B a_{w}}+\frac{C}{1-D a_{w}}\right] a_{w}$ & $\begin{array}{l}\text { (Popovski and Mitrevski, } \\
\text { 2004) }\end{array}$ \\
\hline
\end{tabular}


The correlation coefficient (r) was one of the primary criteria for selecting the best equation to fit the four models to the experimental data. In addition to $r$, the statistical parameters mean relative error (MRE) as a percentage was used to determine the quality of the fit (Foo and Hameed, 2010).

Levenberg-Marquardt nonlinear optimization method using appropriate software is used for the calculation of model coefficients that describe the equilibrium curves and their statistical parameters: mean relative error (MRE) and the correlation coefficient (r).

Mean Relative Error:

$$
\text { MRE }=\frac{100}{N} \sum_{i=1}^{N}\left|\frac{{ }_{\text {eq }_{i, \text { exp }}}-X_{\text {eq }_{i, p r e d}}}{X_{\text {eq }_{i} \text { exp }}}\right|
$$

Correlation coefficient:

$$
r=\sqrt{\frac{\sum_{i=1}^{N}\left(X e q_{i, \text { pred }}-\overline{X e q}_{i, \exp }\right)^{2}}{\sum_{i=1}^{N}\left(X e q_{i, \exp }-\overline{X e q}_{i, \exp }\right)^{2}}}
$$

Where:

$$
\begin{aligned}
& X_{\text {eq }}{ }_{\text {, exp }} \text { ith Experimental moisture content (\%d.b), } \\
& X_{\text {eq }}{ }_{\text {, pred }} \text { ith Predicted moisture content (\%d.b). }
\end{aligned}
$$

\section{Determination of the optimal conditions of storage}

The study of the sorption isotherms enables us to know the optimal relative equilibrium moisture for the conservation of a product as well as the water content of equilibrium to reach at the end of the drying. Also, it gives users with accurate information to handle a product during storage and conservation (Bolin, 1980).

For this purpose, the optimal water activity of conservation $\left(a_{\text {wop }}\right)$ was dogged. The whole of the experimental points is gathered on the same graph. Then, we model the isotherm of sorption by a polynomial equation of the third degree. The part closes to horizontality corresponds to the zone of better stability of the product. This process of calculation consists in making a polynomial decomposition of the equilibrium moisture content $X_{e q}$, for the whole of the experimental results, according to the water activity. This makes it possible to calculate the value for which the derivative second of 
$X_{e q}$ is cancelled "inflection point" and consequently optimal relative humidity for conservation.

\section{Differential enthalpy and differential entropy of sorption}

The differential enthalpy or isosteric heat of sorption $\left(\Delta H_{d}\right)$ indicates the state of absorbed water by the solid material. The net isosteric heat of sorption $\left(\Delta h_{d}\right)$ represents the quantity of energy exceeding the heat of vaporization of water $\left(\Delta H_{\text {vap }}\right.$ ) associated with the sorption process.

$$
\Delta h_{d}=\Delta H_{d}-\Delta H_{\text {vap }}
$$

The net isosteric heat of sorption can be calculated from the experimental data using the Clausius-Clapeyron equation (Lamharrar et al., 2007).

$$
\left[\frac{d\left(\ln a_{w}\right)}{d(1 / T)}\right]_{X_{\text {eq }}}=\frac{-\Delta h_{d}}{R}
$$

Where:

T Absolute temperature (K)

R Universal gas constant $(8.3145 \mathrm{~J} / \mathrm{mol} / \mathrm{K})$

This relation allows determining the isotherms at various temperatures in order to calculate the variation logarithmic curve of the water activity according to the reverse of the temperature, for a water content fixed. However, starting from the modified equations, it is possible to obtain an analytical expression of the heat of sorption $\Delta h_{d}$. This approach assumes that isosteric heat $\Delta \mathrm{H}_{\mathrm{d}}$ does not vary with the temperature (Tsami, 1991).The relationship between the net isosteric heat $\Delta h_{d}$ and the differential entropy $\Delta S_{d}$ of sorption is given by:

$$
\left(-\ln \mathrm{a}_{\mathrm{w}}\right)_{\mathrm{X}_{\mathrm{eq}}}=\frac{\Delta h_{d}}{\mathrm{R} \cdot T}-\frac{\Delta \mathrm{S}_{\mathrm{d}}}{\mathrm{R}}
$$

The experimental sorption isotherm data was plotting in the form of $\ln \left(a_{w}\right)$ versus $\frac{1}{T}$ for specific moisture content $\left(\mathrm{X}_{\mathrm{eq}}\right)$. We determined $\Delta h_{d}$ from the slope $\left(\frac{\Delta h_{d}}{R}\right)$ and $\Delta S_{d}$ from the intercept $\left(\frac{\Delta S_{d}}{R}\right)$. Applying this at different moisture contents allowed determining the dependence on $\Delta h_{d}$ and $\Delta S_{d}$. 


\section{Enthalpy-Entropy Compensation Theory}

According to the theory of compensation, the linear relationship between the enthalpy $\Delta h_{d}$ and the entropy $\Delta S_{d}$ for a specific reaction are given by:

$$
\Delta h_{d}=T_{\beta} \cdot \Delta S_{d}+\Delta G_{\beta}
$$

The isokinetic temperature $\left({ }^{T_{\beta}}\right)$ is a characteristic property of the food surface whose dimension is absolute temperature. It represents the temperature to which all the reactions of the series proceed to the same rate. The free energy ( ${ }^{\Delta G_{\beta}}$ ) provides a criterion to evaluate if the process of the water sorption is spontaneous $\left(-\Delta G_{\beta}\right)$ or not $\left({ }^{+\Delta G_{\beta}}\right)$. This process is repeated for several values of equilibrium relative humidity with an aim of underlining the relation between the differential entropy of sorption and the equilibrium moisture content of the studied product. The isokinetic temperature $\left({ }^{T_{\beta}}\right)$ and constant $\left({ }^{\Delta G_{\beta}}\right)$ were calculated using linear regression (Naji et al., 2010).

\section{Results and discussion}

\section{Sorption and desorption isotherms}

The equilibrium moisture content increases with decreasing temperature at constant water activity (Figure 1). The sorption isotherms present the characteristic S-shaped curve (Type II), typical of sorption isotherms of many plants and food materials (Park et al., 2002; Kouhila et al., 2002; Lahsasni et al., 2004; Ait Mohamed et al., 2005; Jamali et al., 2006; Kouassi Ernest et al 2015).
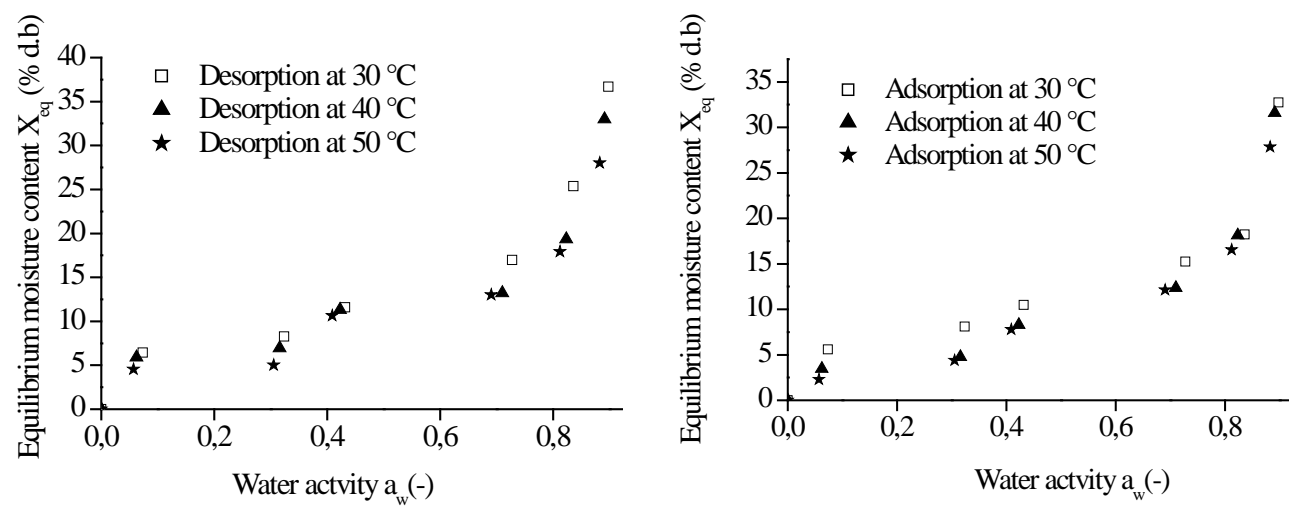

Figure 1: Sorption isotherms of Urtica dioica leaves at 30,40 and $50{ }^{\circ} \mathrm{C}$ 
The presentation of sorption and desorption experimental data in the same plot show that the plant does not have the same hygroscopic equilibrium behavior (Figure 2). The phenomenon of desorption-sorption is irreversible. For the same constant relative moisture, the water content of desorption is higher than that of adsorption. Indeed, there exists a phenomenon of hysteresis. This characteristic is visible for Urtica dioica leaves.

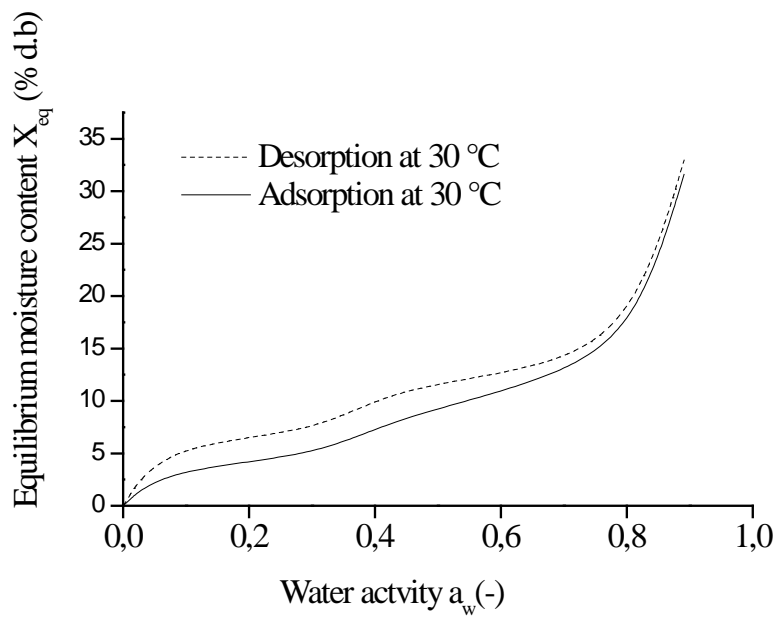

Figure 2: Sorption hysteresis phenomenon of Urtica dioica leaves

Several hypotheses have been put to explain hysteresis. One of it is an analogy with a sponge. When the pores do not contain any more water, adsorption does not make it possible to recover the totality of initial water since this one imprisons air in the pores. Another hypothesis states that hysteresis in the sorption isotherm is a consequence of variation in the fraction of bound water present in the adsorption and desorption processes. The bound fraction being always larger on desorption than on adsorption (Sherman, 1947).

\section{Modeling of sorption experimental data}

The results of non linear regression analysis of fitting the sorption equations to experimental data of Urtica dioica leaves was at three temperatures are presented in Table 2. For all the models tested, parameters $\mathrm{A}, \mathrm{B}$ and $\mathrm{C}$ are found to be temperature dependent. For desorption isotherms, Enderby model is found to be the best estimator for predicting the equilibrium moisture of the Urtica dioica leaves. This model gives the highest correlation coefficient (r) of 0.9981 and mean relative error MRE (4.3075\%) at $\theta=30^{\circ} \mathrm{C}$. For adsorption isotherms, Peleg model is found to be the best estimator for predicting the equilibrium moisture of Urtica dioica 
leaves. This models gives the highest (r) of 0.9967and the MRE (6.6280\%) at $\theta=50^{\circ} \mathrm{C}$.

Table 2: Estimated model coefficients, $r$, MRE of six equation model fitted to sorption isotherm of Urtica dioica leaves

\begin{tabular}{|c|c|c|c|c|c|c|c|}
\hline Model & Parameters & \multicolumn{3}{|c|}{ Desorption } & \multicolumn{3}{|c|}{ Adsorption } \\
\hline \multirow{6}{*}{ GAB } & $\boldsymbol{\theta}\left({ }^{\circ} \mathbf{C}\right)$ & 30 & 40 & 50 & 30 & 40 & 50 \\
\hline & A & 5.5252 & 4.2602 & 4.5941 & 4.4702 & 3.5516 & 3.7865 \\
\hline & B & 0.9432 & 0.9706 & 0.9426 & 0.9487 & 0.9944 & 0.9771 \\
\hline & C & 390.1938 & 110.2862 & 380.6512 & 68.6528 & 412.2234 & 29.0048 \\
\hline & $\mathbf{r}$ & 0.9947 & 0.9721 & 0.9799 & 0.9643 & 0.9934 & 0.9920 \\
\hline & RME & 7.1330 & 16.7363 & 12.1912 & 18.6960 & 8.6848 & 11.0096 \\
\hline \multirow{5}{*}{ Henderson modifié } & A & 0.0028 & 0.0019 & 0.0014 & 0.0023 & 0.0032 & 0.0025 \\
\hline & B & -17.4960 & -15.8693 & -20.5234 & -15.5315 & 1.2706 & -7.0323 \\
\hline & C & 1.1818 & 1.1529 & 1.2235 & 1.2726 & 0.8307 & 0.9293 \\
\hline & $\mathbf{r}$ & 0.9605 & 0.9186 & 0.9489 & 0.9297 & 0.9616 & 0.9725 \\
\hline & RME & 21.7143 & 21.5854 & 33.4118 & 25.0296 & 32.2487 & 25.6404 \\
\hline \multirow{6}{*}{ Peleg } & A & 57.0714 & 95.0904 & 68.5839 & 16.7738 & 94.1110 & 133.8690 \\
\hline & B & 14.0564 & 13.4275 & 14.3752 & 224.0437 & 13.7622 & 16.8128 \\
\hline & C & 8.4645 & 13.4848 & 12.4200 & 0.5139 & 13.9519 & 18.6910 \\
\hline & D & 0.3288 & 0.3403 & 0.5144 & 24.0535 & 0.6584 & 0.9377 \\
\hline & $\mathbf{r}$ & 0.9974 & 0.9933 & 0.9845 & 0.9957 & 0.9955 & 0.9967 \\
\hline & RME & 6.1795 & 9.4255 & 16.9626 & 7.9714 & 13.7854 & 6.6280 \\
\hline \multirow{5}{*}{ Halsey Modifié } & A & 2.7540 & 2.3549 & 1.6014 & 2.4438 & 1.6943 & 1.1292 \\
\hline & B & 0.0301 & 0.0214 & 0.0320 & 0.3480 & 0.0123 & 0.0225 \\
\hline & C & 1.6460 & 1.5653 & 1.6035 & 1.6773 & 1.2729 & 1.3154 \\
\hline & $\mathbf{r}$ & 0.9944 & 0.9718 & 0.9804 & 0.9711 & 0.9900 & 0.9917 \\
\hline & RME & 8.3696 & 15.8939 & 15.2886 & 12.7527 & 12.7076 & 10.0679 \\
\hline \multirow{5}{*}{ Oswin Modifié } & A & 4.6327 & 0.7189 & 2.3978 & 3.1596 & 0.1649 & 1.6449 \\
\hline & B & 0.2442 & 0.2371 & 0.1459 & 0.2421 & 0.1835 & 0.1189 \\
\hline & C & 0.4928 & 0.5147 & 0.4948 & 0.4766 & 0.6580 & 0.6202 \\
\hline & $\mathbf{r}$ & 0.9843 & 0.9539 & 0.9708 & 0.9563 & 0.9817 & 0.9874 \\
\hline & RME & 13.5973 & 21.5854 & 21.3011 & 18.3354 & 20.5685 & 14.8797 \\
\hline \multirow{6}{*}{ Enderby } & A & 316.3100 & 1.8301 & 152.5967 & 121.3757 & 92.8471 & 0.7277 \\
\hline & B & -38.7367 & 1.0478 & -20.3168 & -10.6550 & -14.8069 & 1.0867 \\
\hline & C & 3.6179 & 250.0000 & 2.4319 & 1.1768 & 2.3258 & 18.6217 \\
\hline & D & 0.9878 & -2.8564 & 1.0164 & 1.0609 & 1.0319 & -0.3849 \\
\hline & $\mathbf{r}$ & 0.9981 & 0.9934 & 0.9847 & 0.9954 & 0.9964 & 0.9967 \\
\hline & RME & 4.3075 & 7.7728 & 14.1093 & 6.6280 & 9.8444 & 14.1519 \\
\hline
\end{tabular}

Measurement of optimal water activity of Urtica dioica leaves

A good product deserves quality treatment. The heat and process engineering specialists must provide users with accurate information on how 
to handle a product during storage and conservation. For this purpose, the optimal water activities of conservation $\left(a_{\text {wop }}\right)$ were determined. The sorption isotherm curve can be described as a polynomial equation of the third degree, the central part or "stage" is the best area of product stability (Figure 3).



Figure 3: Determination of optimal water activity for conservation of Urtica dioica leaves

This calculation method consists of decomposing polynomial of equilibrium moisture content Xeq, for all the experimental results for each product based on water activity (equation 7). The value of the optimal water activity for conservation of Urtica dioica leaves is $a_{\text {wop }}=0.36$; the optimal water activities are ranged in (0.3-0.4) (Le Meste et al., 2001).

$$
\mathrm{X}_{\mathrm{eq}}=0.321+73.788 \mathrm{a}_{\mathrm{w}}+-211.159 \mathrm{a}_{\mathrm{w}}{ }^{2}+186.305 \mathrm{a}_{\mathrm{w}}{ }^{3} \quad r=0.93
$$

\section{Enthalpy and entropy of sorption}

The net isosteric heat of sorption $\left(\Delta \mathrm{h}_{\mathrm{d}}\right)$ values are calculated from the equilibrium moisture data at different temperatures using Clausius-clapeyron equation (4). The variation of the heat sorption of Urtica dioica leaves with equilibrium moisture content is shown in Fig. 4.

The net isosteric heat of desorption an adsorption of Urtica dioica leaves can be expressed mathematically as a polynomial function of equilibrium moisture content:

Desorption : $\Delta \mathrm{h}_{\mathrm{d}}=58.5349-5.0950 \mathrm{X}_{\mathrm{eq}}+0.1149 \mathrm{X}_{\mathrm{eq}}^{2} r=0.9979$

Adsorption : $\quad \Delta \mathrm{h}_{\mathrm{d}}=55.3856-5.9170 \mathrm{X}_{\text {eq }}+0.1598 \mathrm{X}_{\text {eq }}^{2} \mathrm{r}=0.9984$ 
The differential entropy $\left(\Delta \mathrm{S}_{\mathrm{d}}\right)$ is plotted as a function of moisture content in Figure 4. Once again, the entropy data display a strong dependence on moisture content. The experimental desorption and adsorption data, respectively, conform to polynomial relation as represented by the equations:

Desorption : $\Delta \mathrm{S}_{\mathrm{d}}=390.6015-65.5339 \mathrm{X}_{\mathrm{eq}}+3.8877 \mathrm{X}_{\text {eq }}^{2}-0.0784 \mathrm{X}_{\text {eq }}^{3}$ $\mathrm{r}=1(11)$

Adsorption : $\Delta \mathrm{S}_{\mathrm{d}}=371.2822-65.2823 \mathrm{X}_{\mathrm{eq}}+3.9958 \mathrm{X}_{\mathrm{eq}}^{2}-0.0817 \mathrm{X}_{\text {eq }}^{3}$ $\mathrm{r}=1(12)$


Figure 4: Net isosteric heat and differential entropy of sorption of Urtica dioica leaves as a function of equilibrium moisture content

\section{Enthalpy-entropy compensation theory}

The $\Delta h_{d}$ and $\Delta S_{d}$ values for adsorption and desorption, at given moisture contents, were calculated by linear regression equation using equation 6. It was assumed that, at specific moisture content, $\Delta h_{d}$ and $\Delta S_{d}$ did not vary with temperature. Figure 5 shows a linear relation, with a correlation of determination $(\mathrm{r}=1)$. This indicates that the compensation exists. The parameters $T_{\beta}$ and $\Delta G_{\beta}$ (Equation 7) were calculated from the data by linear regression, and the values are detailed in Table 3 . 


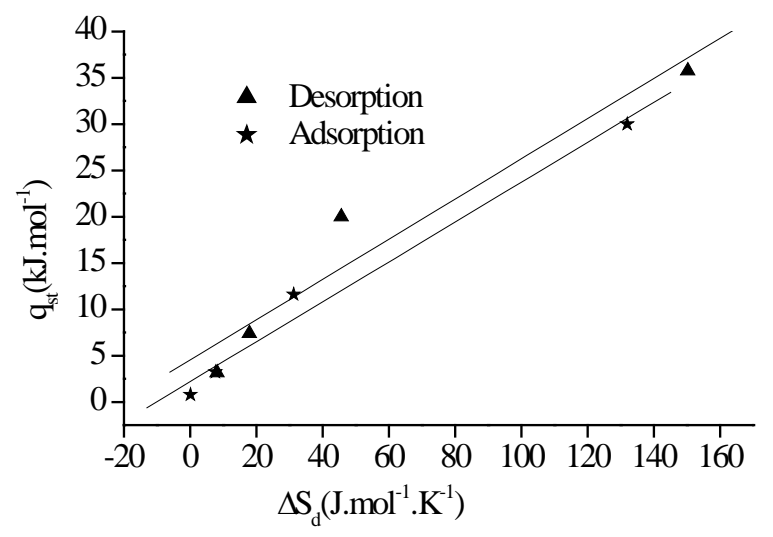

Figure 5: Compensation theory of enthalpy/entropy

Table 3: Characteristic parameters for $\Delta h_{d} / \Delta S_{d}$ Relationship

\begin{tabular}{ccc}
\hline & $\mathrm{T}_{\beta}(\mathrm{K})$ & $\Delta \mathrm{G}_{\beta}\left(\mathrm{J} \cdot \mathrm{mol}^{-1}\right)$ \\
\hline Desorption & 216.90 & 4537.90 \\
Adsorption & 215.12 & 2197.69 \\
\hline
\end{tabular}

\section{Conclusion}

It's now widely accepted that sorption data provide valuable information for industrial drying in order to preserve and store the seasonal plants and make them available to consumers all year round. The sorption data may be used not only for the identification of the optimum residual moisture content of the final product, but also for the calculation of the drying time of hygroscopic substances.

The moisture sorption curves of Urtica dioica leaves were experimentally investigated at three temperatures 30,40 and $50{ }^{\circ} \mathrm{C}$. The isotherms have a sigmoid shape (Type II) which is common for many hygroscopic products. The hysteresis phenomenon was distinctly observed. Among the sorption models chosen, the Enderby model was the best model describing the equilibrium moisture data for desorption, and the Peleg model was the most suitable to estimate adsorption isotherms. The optimal water activities of conservation were determined. Net isosteric heat of sorption and differential entropy values of Urtica dioica leaves were found to be a polynomial function of moisture content for desorption and adsorption. Enthalpy-entropy compensation theory could be successfully applied to the moisture sorption behaviour of dioica leaves. 


\section{References :}

Ait Mohamed, L., Kouhila, M., Jamali, A., Lahsasni, S., Mahrouz, M., 2005. Moisture sorption isotherms and heat of sorption of bitter orange leaves (Citrus aurantium), Journal of Food Engineering. 67, 491-498.

Al-Muhtaseb, A.H., McMinn, W.A.M., Magee, T.R.A., 2004. Water sorption isotherms of starch powders Part1: mathematical description of experimental data, Journal of Food Engineering. 61, 297-307.

Arsalan, N., Togrul, H., 2006. The fitting of various models to water sorption isotherms of tea stored in a chamber under controlled temperature and humidity, Journal of Stored Products research. 42(2) 112-135.

Bellakhdar, J., 1997. La Pharmacopée marocaine traditionnelle, Médecine arabe ancienne et savoirs populaires. Ibis Press. Paris, 764.

Bolin, H.R., 1980. Relation of Moisture to Water Activity in Prunes and Raisin, J. Food. Sci. 46, 1190.

Foo, K.Y., Hameed, B.H., 2010. Insights into the modelling of adsorption isotherm systems, Chemical Engineering Journal. 156, 2-10.

Greenspan, L., 1977. Humidity fixed points of binary saturated aqueous solutions, Journal of Research, National Bureau of Standards, A Physics and Chemistry. 81(1), 92-93.

Iglesias, H., Chirife, J., 1976. Prediction of effect of temperature on water sorption isotherms of food materials, Journal of Food Technology. 11, 109116.

Jamali, A., Kouhila, M., Ait Mohamed, L., Idlimam, A., Lamharrar, A., 2006. Moisture adsorption-desorption isotherms of Citrus reticulata leaves at three temperatures, Journal of Food Engineering. 77(1), 71-78.

Kouassi Ernest K., Djédjro Clément A., N’Guessan Verdier A., Nogbou Emmanuel A., Lamine Sébastien N., (2015). Isotherme d'absorption d'eau des fèves de cacao (Théobroma cacao) Marchand. European Scientific Journal. 11(12), 355-370.

Kouhila, M., Kechaou, N., Otmani, M., Fliyou, M., Lahsasni, S., 2002. Experimental study of sorption isotherms and drying kinetics of Moroccan Eucalyptus Globulus. Drying Technology. 20(10), 2027-2039.

Krystofova, O., Adam, V., Babula, P., Zehnalek, J., Beklova, M., Havel, L., Kizek, R., 2010. Effects of various doses of selenite on stinging nettle (Urtica dioica L.). Int J Environ Res Public Health. 7, 3804-3815.

Lahsasni, S., Kouhila, M., Mahrouz, M.,2004. Adsorption-desorption isotherms and heat of sorption of prickly pear fruit (Opuntia ficus indica), Energy Conversion and Management. 45, 249-261.

Lamharrar, A., Idlimam, A., Kouhila, M., 2007. Thermodynamic properties and moisture isotherms of Artemisia herba-alba Rev. Energ. Ren. 10(3), $311-320$. 
Le Meste, M., Roudaut, G., Chiotelli, E., Simatos, D., Colas, B., 2001. Proprietes fonctionnelles de l'eau dans les aliments, Industries Alimentaires et Agricoles, 118(5), 21-28.

Naji, A., Idlimam, A., Kouhila, M., 2010. Sorption isotherms and thermodynamic properties of powdered milk. Chem.Eng.Comm. 197 (8), 1109-1125.

Oswin, C.R., 1946. The kinetics of package life. III. Isotherm, Journal of the Society of Chemical Industry, 65, 419-421.

Park, K.J., Vohnikova, Z., Brod, F.P.R., 2002. Evaluation of drying parameters and desorption isotherms of garden mint leaves (Mentha crispa L.), Journal of food engineering. 51, 193-199.

Peleg, M., 1993. Assessment of a semi-empirical four parameter general model for sigmoid moisture sorption isotherms, Journal of Food Process Engineering. 16, 21-37.

Popovski, D., Mitrevski, V., 2004. Some new four parameter models for moisture sorption isotherms, EJEAF Che. ISSN, 1579-4377.

Sherman, E.S., 1947. Sorption of water vapour by proteins and high polymers, J. Am. Chem. Soc. 69(3), 646-651.

Thompson,T.L., Peart, R.M., Foster, G.H., 1986. Mathematical simulation of corn drying a new model, Transactions of the American Society of Agricultural Engineers. 11, 582-586.

Tsami, E.,1991. Net Isosteric Heat of Sorption in Dried Fruits, Journal of Food Engineering. 14, 327-335.

Van den Berg, C., Bruin, S., 1981. Water activity and its estimation in food systems: theoretical aspects. In L. B. Rockland \& G. F. Stewart (Eds.), Water activity: influences on food quality, New York: Academic Press. 147-177. 